\title{
Prophylactic tricuspid annuloplasty in patients with dilated tricuspid annulus undergoing mitral valve surgery
}

\author{
Umberto Benedetto, MD, Giovanni Melina, MD, Emiliano Angeloni, MD, Simone Refice, MD, \\ Antonino Roscitano, MD, Cosimo Comito, MD, and Riccardo Sinatra, MD
}

\begin{abstract}
Objective: Progression of functional tricuspid regurgitation is not uncommon after mitral valve surgery and is associated with poor outcomes. We tested the hypothesis that concomitant tricuspid valve annuloplasty in patients with tricuspid annulus dilatation $(\geq 40 \mathrm{~mm})$ prevents tricuspid regurgitation progression after mitral valve surgery.
\end{abstract}

\begin{abstract}
Methods: We enrolled 44 patients undergoing mitral valve surgery (both repair or replacement) showing less than moderate $(\leq+2)$ tricuspid regurgitation and dilated tricuspid annulus $(\geq 40 \mathrm{~mm})$ at preoperative echocardiography. They were randomized to receive $(n=22)$ or not receive $(n=22)$ concomitant tricuspid annuloplasty (Cosgrove-Edwards annuloplasty ring; Edwards Lifesciences, Irvine, Calif) at the time of mitral valve surgery. Clinical and echocardiographic follow-up was $100 \%$ completed at 12 months after surgery.
\end{abstract}

Results: Preoperative clinical and echocardiographic characteristics were comparable in the 2 groups. Operative mortality was $4.4 \%$ (1 death in each group). At 12 months follow-up, tricuspid regurgitation was absent in $71 \%$ $(\mathrm{n}=15)$ versus $19 \%(\mathrm{n}=4)$ of patients in the treatment and control groups, respectively $(P=.001)$. Moderate to severe tricuspid regurgitation $(\geq+3)$ was present in $0 \%$ versus $28 \%(n=6)$ of patients in the treatment and control groups, respectively $(P=.02)$. Pulmonary artery systolic pressure significantly decreased from baseline in all cases $(P<.001)$ and was comparable in the 2 groups $(41 \pm 8 \mathrm{~mm} \mathrm{Hg}$ vs $40 \pm 5 \mathrm{~mm} \mathrm{Hg} ; P=.4)$. Right ventricular reverse remodeling was marked in the treatment group (right ventricular long axis: $71 \pm 7 \mathrm{~mm}$ vs $65 \pm 8$ $\mathrm{mm} ; P=.01$; short axis: $33 \pm 4 \mathrm{~mm}$ vs $27 \pm 5 \mathrm{~mm} ; P=.001$ ) but only minimal in the control group (right ventricular long axis: $72 \pm 6 \mathrm{~mm}$ vs $70 \pm 7 \mathrm{~mm} ; P=.08$; short axis: $34 \pm 5 \mathrm{~mm}$ vs $33 \pm 5 \mathrm{~mm} ; P=.1$ ). The 6-minute walk test improved from baseline in both groups $(P<.001)$, but this improvement was greater in the treatment group $(+115 \pm 23 \mathrm{~m}$ from baseline vs $+75 \pm 35 \mathrm{~m} ; P=.008)$.

Conclusions: Prophylactic tricuspid valve annuloplasty in patients with dilated tricuspid annulus undergoing mitral valve surgery was associated with a reduced rate of tricuspid regurgitation progression, improved right ventricular remodeling, and better functional outcomes. (J Thorac Cardiovasc Surg 2012;143:632-8)

Functional or secondary tricuspid regurgitation (TR) refers to TR typically seen in association with left-sided valve dysfunction and occurring in the absence of intrinsic pathology of the tricuspid valve (TV) leaflets or chordae. Historically, functional TR was managed conservatively because it was sometimes observed to decrease or even disappear after surgical correction of mitral valve disease. ${ }^{1,2}$ However, moderate to severe late functional TR has been reported in up to one third of patients after isolated mitral surgery for rheumatic, ${ }^{3}$ functional, ${ }^{4}$ ischemic, ${ }^{4}$ and degenerative mitral valve disease. ${ }^{5}$ Severe TR late after cardiac surgery

From the Cardiac Surgery Department, University of Rome Sapienza, Azienda Ospedaliera S Andrea, Rome, Italy.

Disclosures: Authors have nothing to disclose with regard to commercial support.

Read at the 91st Annual Meeting of The American Association for Thoracic Surgery, Philadelphia, Pennsylvania, May 7-11, 2011.

Received for publication May 2, 2011; revisions received Oct 21, 2011; accepted for publication Dec 6, 2011; available ahead of print Jan 13, 2012.

Address for reprints: Umberto Benedetto, MD, Cardiac Surgery Department, II School of Medicine, University of Rome Sapienza, Via di Grottarossa 1039 (E-mail: u2benedetto@libero.it).

$0022-5223 / \$ 36.00$

Copyright $(2) 2012$ by The American Association for Thoracic Surgery

doi:10.1016/j.jtcvs.2011.12.006 is associated with substantial morbidity and mortality, ${ }^{6,7}$ and there is some evidence to suggest that even moderate degrees of functional TR may have an adverse impact on survival and functional outcome. ${ }^{8}$ Concomitant TV annuloplasty at the time of mitral surgery is a safe and effective method of preventing progression of functional $\mathrm{TR},{ }^{5-9}$ and consensus guidelines therefore recommend tricuspid repair for moderate TR. ${ }^{10,11}$ Because TR is highly dynamic, ${ }^{12}$ tricuspid annular dilatation of $40 \mathrm{~mm}$ or greater has also been proposed as an indication for prophylactic tricuspid annuloplasty ${ }^{10}$ because it seems to be a risk factor for the development of late functional TR. ${ }^{5}$ Unlike TR grade, tricuspid annular dilatation is a relatively objective measurement that can be assessed independently of the patient's hemodynamic status. ${ }^{13}$

Although significant reductions in grade and progression of functional TR after cardiac surgery have been observed with TV annuloplasty, ${ }^{5}$ the benefit of prophylactic TV annuloplasty remains controversial. We therefore designed this study to test the hypothesis that concomitant TV annuloplasty in patients with tricuspid annulus dilatation $(\geq 40 \mathrm{~mm})$ prevents TR progression after mitral valve 


$$
\begin{aligned}
& \text { Abbreviations and Acronyms } \\
& \begin{aligned}
\text { NYHA } & =\text { New York Heart Association } \\
\text { RV } & =\text { right ventricular } \\
\text { TR } & =\text { tricuspid regurgitation } \\
\text { TV } & =\text { tricuspid valve }
\end{aligned}
\end{aligned}
$$

surgery and to evaluate whether this is associated with improved right ventricular (RV) remodeling or a functional benefit.

\section{PATIENTS AND METHODS}

Among consecutive patients undergoing mitral valve surgery (both repair or replacement) combined or not combined with coronary artery bypass grafting between May 2008 and September 2009, 56 patients were enrolled who presented the following criteria at preoperative echocardiographic examination: (1) less than moderate $(\leq+2)$ functional TR and (2) dilated tricuspid annulus ( $\geq 40 \mathrm{~mm}$ ). Exclusion criteria were urgent operation, presence of pacemaker leads through the tricuspid annulus, acute endocarditis, and previous surgical procedure on TV.

A total of 44 patients were randomized to receive $(n=22$ treatment group) or not receive ( $\mathrm{n}=22$, control group) concomitant TV annuloplasty at the time of mitral valve surgery. The local ethics committee approved this study, and each patient signed an informed consent form.

\section{Clinical Assessment}

At baseline and the 12-month follow-up, functional New York Heart Association (NYHA) class was assessed and 6-minute walk test was performed in every patient by a physician who was blinded to the treatment assigned. The 6-minute walk test was performed on a level surface. Patients were instructed to cover the greatest distance possible during the allotted time, at a self-determined walking speed, pausing to rest when needed. The distance covered was measured by a body-borne pedometer, as previously reported by Roul and colleagues. ${ }^{14}$

Medications assumed at follow-up were reported, including diuretics (furosemide and hydrochlorothiazide), calcium-channel blockers, $\beta$-blockers, and angiotensin-converting enzyme inhibitors/angiotensin receptor blockers.

\section{Echocardiography}

A transthoracic echocardiogram was performed within 7 days before the operation and at 1-year follow-up. Images were obtained using a HewlettPackard (Palo Alto, Calif) Sonos 2500 or 5500 imaging system equipped with a $2.5-\mathrm{MHz}$ transducer in the parasternal and apical views (standard long-axis, 2-chamber, and 4-chamber images). The left atrial diameter and left ventricular dimensions (end-systolic and end-diastolic diameters) were determined from parasternal M-mode acquisitions. Color flow was applied in the apical views to evaluate TR. The maximal TR jet area visualized using color Doppler flow mapping was used for TR quantification, with a TR jet-to-right atrial area ratio of less than $10 \%=$ grade $1+, 10 \%$ to $20 \%=2+, 20 \%$ to $40 \%=3+$, and greater than $40 \%=4+.{ }^{15}$ Systolic reversal of hepatic venous flow was also used as a criterion for $4+\mathrm{TR}$. The peak systolic TR jet velocity measured by $\mathrm{CW}$.

Doppler was used to calculate the TR peak pressure gradient using the

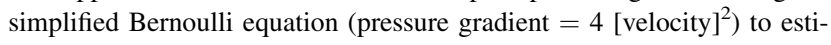
mate the peak systolic pulmonary artery pressure. Assessment of the RV was made as previously described. ${ }^{16}$ From the apical 4-chamber view, the ultrasound beam was oriented to obtain the maximum dimensions of the RV chamber. The middle third of the RV was identified as lying below the inflow tract region. A measurement of the maximum dimension of this portion of the chamber was recorded as the RV short axis. The major axis of the RV was also measured from this view and defined as the distance between the RV apex to the mid-point of the TV annulus. The TV annular dimension was measured as the point of attachment of the septal and posterior leaflets to the atrioventricular junction in the transthoracic apical 4-chamber view in late diastole at the time of maximal tricuspid opening. Because the results of annuloplasty with an annuloplasty ring are generally apparent, the physician who performed the echocardiographic follow-up was not blinded to treatment.

\section{Surgical Procedure}

All patients were operated via a full median sternotomy under cardiopulmonary bypass at normothermia. Double venous cannulation was used. Myocardial protection consisted of antegrade cold-blood cardioplegia. Patients with an indication for revascularization underwent coronary artery bypass grafting first. Patients with a history of atrial fibrillation and a left atrium diameter less than $60 \mathrm{~cm}$ underwent left atrial lesion set of the Maze procedure by means of bipolar radiofrequency.

The mitral valve was approached through a standard left atriotomy. In the case of degenerative disease, mitral valve reconstruction was conducted by using standard Carpentier techniques or artificial chordae implantation. Mitral annuloplasty was routinely performed using a flexible ring (Cosgrove-Edwards Annuloplasty System; Edwards Lifesciences, Irvine, Calif), and ring size was determined by means of standard measurement of the surface of the anterior leaflet. In case of ischemic functional mitral regurgitation, a remodeling annuloplasty using the Carpentier-McCarthyAdams IMR ETlogix annuloplasty ring (Edwards Lifesciences) was performed. Mitral valve replacement was routinely performed in rheumatic mitral disease.

In the treatment group, the right atrium was opened horizontally in all patients after left atrium closure. A remodeling tricuspid annuloplasty with the flexible Cosgrove-Edwards Annuloplasty System (Edwards Lifesciences) was performed. The appropriate size was selected on the basis of the length of the attachment of the tricuspid septal leaflet. Transesophageal echocardiography was used to confirm the competence of the repair.

\section{Statistical Analysis}

The primary end point was the occurrence of moderate to severe $(\geq 3+)$ functional TR at 1 year follow-up. A sample size of approximately 19 patients per arm was estimated on the basis of a prevalence of $40 \%$ for the primary outcome, as previously shown, ${ }^{17}$ a $35 \%$ clinically meaningful difference between groups, and $80 \%$ power at a 0.05 significance level to reject the null hypothesis of equal rate for treatment versus control group. A computer-generated random list (GraphPad Software, Inc, La Jolla, Calif) was used to allocate patients in each group on the day of surgery.

For categoric data, the statistical evaluation of the results was carried out by means of the Fisher exact test to calculate an exact $P$ value for a $2 \times 2$ frequency table with a small number of expected frequencies, for which the chi-square test was not appropriate.

For continuous data, 2 (between 2 treatment groups) $\times 2$ (repeated measures with 2 levels: basal and second evaluation) analysis of variance was used to (1) compare basal values between the 2 groups, (2) evaluate longitudinal changes within each group, and (3) compare the effects of treatments (treatment vs control) on echocardiographic parameters and clinical outcomes. Data were reported as mean \pm standard deviation. Statistical analyses were performed using the Statistical Package for the Social Sciences, version 11 (SPSS Inc, Chicago, Ill).

\section{RESULTS}

\section{Preoperative Characteristic}

Preoperative patient demographics are listed in Table 1. There was no statistically significant difference between the 2 groups with regard to age, sex, history of atrial 
TABLE 1. Baseline clinical characteristics

\begin{tabular}{|c|c|c|c|}
\hline & $\begin{array}{c}\text { Treatment } \\
\text { group } \\
(\mathrm{n}=\mathbf{2 2}) \\
\end{array}$ & $\begin{array}{c}\text { Control } \\
\text { group } \\
(\mathrm{n}=22)\end{array}$ & $\boldsymbol{P}$ \\
\hline Female, n y $(\%)$ & $9(40 \%)$ & $11(50 \%)$ & .7 \\
\hline Mean age $(y)$ & $64 \pm 15$ & $68 \pm 19$ & .44 \\
\hline Prior cardiac surgery, $\mathrm{n}(\%)$ & $1(4 \%)$ & $1(4 \%)$ & .4 \\
\hline Prior myocardial infarction, $\mathrm{n}(\%)$ & $3(14 \%)$ & $6(27 \%)$ & .5 \\
\hline Diabetes, n (\%) & $7(32 \%)$ & $4(18 \%)$ & .4 \\
\hline Renal failure, $\mathrm{n}(\%)$ & $1(4 \%)$ & $0(0 \%)$ & .9 \\
\hline Hypertension, $\mathrm{n}(\%)$ & $15(68 \%)$ & $11(50 \%)$ & .3 \\
\hline PVD, n (\%) & $3(14 \%)$ & $4(18 \%)$ & 1 \\
\hline History of atrial fibrillation, $\mathrm{n}(\%)$ & $9(40 \%)$ & $12(54 \%)$ & .5 \\
\hline Cause of MV disease, $\mathrm{n}(\%)$ & & & 6 \\
\hline Degenerative & $8(36 \%)$ & $8(36 \%)$ & \\
\hline Rheumatic & $8(36 \%)$ & $6(27 \%)$ & \\
\hline Functional & $5(22 \%)$ & $7(32 \%)$ & \\
\hline Prosthesis dysfunction & $0(0 \%)$ & $1(4 \%)$ & \\
\hline Failure of MV repair & $1(4 \%)$ & $0(0 \%)$ & \\
\hline MV lesion, $\mathrm{n}(\%)$ & & & .9 \\
\hline Regurgitation & $16(72 \%)$ & $15(68 \%)$ & \\
\hline Stenosis & $2(9 \%)$ & $3(14 \%)$ & \\
\hline Mixed & $4(18 \%)$ & $4(18 \%)$ & \\
\hline NYHA functional class, $\mathrm{n}(\%)$ & & & .5 \\
\hline I-II & $5(22 \%)$ & $8(36 \%)$ & \\
\hline III-IV & $17(77 \%)$ & $14(63 \%)$ & \\
\hline 6-min walk test $(\mathrm{m})$ & $354 \pm 57$ & $361 \pm 49$ & .6 \\
\hline
\end{tabular}

fibrillation, previous myocardial infarction, NYHA functional class, and 6-minute walk test. The underlying cause and valvular lesion of mitral valve were similar in both groups, with the predominant lesion being degenerative mitral regurgitation. Preoperative echocardiographic characteristics are presented in Table 2. Left ventricular dimensions and function were comparable between the 2 cohorts. TR grade was similar between both cohorts, as were RV dimensions.

TABLE 2. Baseline echocardiographic characteristics

\begin{tabular}{lccl}
\hline & $\begin{array}{c}\text { Treatment } \\
\text { group }(\mathbf{n}=\mathbf{2 2})\end{array}$ & $\begin{array}{c}\text { Control } \\
\text { group }(\mathbf{n}=\mathbf{2 2})\end{array}$ & $\boldsymbol{P}$ \\
\hline Left atrial diameter (mm) & $48 \pm 9$ & $47 \pm 8$ & .7 \\
LV end-diastolic diameter (mm) & $60 \pm 5$ & $61 \pm 7$ & .5 \\
LV end-systolic diameter (mm) & $39 \pm 9$ & $37 \pm 7$ & .4 \\
LV ejection fraction (\%) & $51 \pm 8$ & $55 \pm 7$ & .09 \\
RV long axis (mm) & $71 \pm 7$ & $72 \pm 6$ & .6 \\
RV short axis (mm) & $33 \pm 4$ & $34 \pm 5$ & .47 \\
TV annulus (mm) & $43 \pm 3$ & $44 \pm 3$ & .28 \\
TR grade, n (\%) & $9(41 \%)$ & $12(54 \%)$ & .6 \\
$\quad$ 0+ & $7(32 \%)$ & $5(23 \%)$ & \\
$\quad$ 1+ & $6(27 \%)$ & $5(23 \%)$ & \\
$\quad$ 2+ & $48 \pm 4$ & $49 \pm 4$ & .47 \\
Pulmonary artery systolic & & & \\
$\quad$ pressure (mm Hg) & & & \\
LV, Left ventricular; $R V$, right ventricular; $T V$, tricuspid valve; $T R$, tricuspid \\
regurgitation.
\end{tabular}

TABLE 3. Twelve-month follow-up echocardiographic characteristics

\begin{tabular}{|c|c|c|c|}
\hline & $\begin{array}{c}\text { Treatment } \\
\text { group }(n=21)\end{array}$ & $\begin{array}{c}\text { Control } \\
\text { group }(n=21)\end{array}$ & $\boldsymbol{P}$ \\
\hline Left atrial diameter $(\mathrm{mm})$ & $41 \pm 4$ & $40 \pm 6$ & .5 \\
\hline LV end-diastolic diameter (mm) & $56 \pm 7$ & $57 \pm 8$ & .6 \\
\hline LV end-systolic diameter (mm) & $34 \pm 10$ & $35 \pm 5$ & .6 \\
\hline LV ejection fraction $(\%)$ & $50 \pm 8$ & $51 \pm 6$ & .7 \\
\hline $\mathrm{RV}$ long axis $(\mathrm{mm})$ & $65 \pm 8$ & $70 \pm 7$ & .03 \\
\hline RV short axis (mm) & $27 \pm 5$ & $33 \pm 8$ & .005 \\
\hline TV annulus (mm) & $36 \pm 4$ & $41 \pm 3$ & .01 \\
\hline TR grade, $\mathrm{n}(\%)$ & & & .007 \\
\hline $0+$ & $15(72 \%)$ & $4(19 \%)$ & \\
\hline $1+$ & $3(14 \%)$ & $5(24 \%)$ & \\
\hline $2+$ & $3(14 \%)$ & $6(29 \%)$ & \\
\hline $3+$ & $0(0 \%)$ & $5(24 \%)$ & \\
\hline $4+$ & $0(0 \%)$ & $1(4 \%)$ & \\
\hline $\begin{array}{c}\text { Pulmonary artery systolic } \\
\text { pressure }(\mathrm{mm} \mathrm{Hg})\end{array}$ & $41 \pm 8$ & $40 \pm 5$ & 6 \\
\hline
\end{tabular}

\section{Operative Outcomes}

The rate of mitral valve repair was similar in both treatment $(54 \%, \mathrm{n}=12)$ and control $(63 \%, \mathrm{n}=14)$ groups $(P=.75)$. Coronary artery bypass grafting was performed in both treatment $(22 \%, \mathrm{n}=5)$ and control $(32 \%, \mathrm{n}=7)$ groups $(P=.73)$. Left atrial lesion set of the Maze procedure was performed in both treatment $(27 \%, \mathrm{n}=6)$ and control $(41 \%, \mathrm{n}=9)$ groups $(P=.52)$. Cardiopulmonary bypass time and clamp time were slightly increased in the treatment group: $139 \pm 37$ versus $120 \pm 66$ minutes, respectively $(P=.07)$. The tricuspid median ring size used in the treatment group was $32 \mathrm{~mm}$. No correlation was found between ring size and TR grade at follow-up (nonparametric $P=.2)$. The 30-day mortality was the same in the treatment $(4.4 \%, \mathrm{n}=1)$ and control $(4.4 \%, \mathrm{n}=1)$ groups, with death attributed to low cardiac output syndrome and pneumonia, respectively, in patients undergoing operation for functional mitral regurgitation. The mean length was the same in the treatment ( 7 days) and control ( 7 days) groups $(P=1)$.

\section{Follow-up}

All operative survivors completed the 12-month followup. Echocardiographic follow-up is presented in Table 3. All patients who had mitral valve repair showed no late recurrent mitral regurgitation of greater than grade $1+$. No mitral valve prosthesis dysfunction was detected. As expected, after surgical intervention on the mitral valve, a reduction in left atrial and left ventricular dimensions was observed in both groups, as well as in pulmonary artery systolic pressure, which significantly decreased from baseline in both groups $(P<.001)$.

TR was more often absent in the treatment group $(71 \%$, $\mathrm{n}=15)$ than in the control group $(19 \%, \mathrm{n}=4)(P=.001)$. New onset of moderate to severe TR $(\geq+3)$ was completely absent in the treatment group $(0 \%, \mathrm{n}=0)$ but was observed 


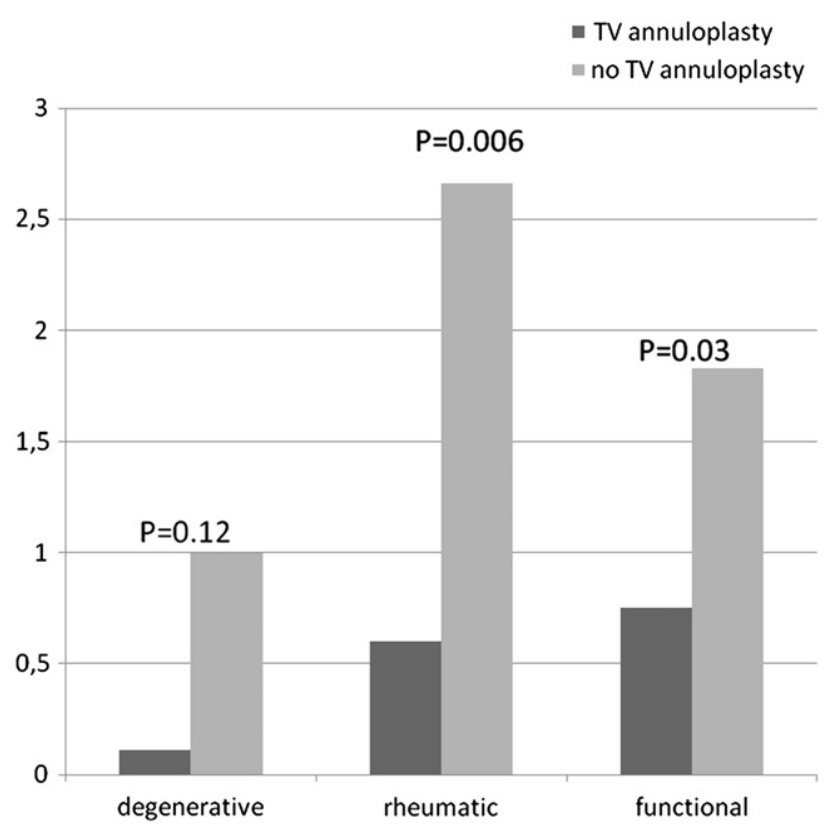

FIGURE 1. Mean TR grade at follow-up according to the cause of mitral valve disease. $T V$, Tricuspid valve.

in the control group $(28 \%, \mathrm{n}=6)(P=.02)$. The mean grade of TR in treatment and control groups according to mitral valve cause is shown in Figure 1.

$\mathrm{RV}$ reverse remodeling was substantial in the treatment group (RV long axis: $71 \pm 7 \mathrm{~mm}$ vs $65 \pm 8 \mathrm{~mm} ; P=.01$; RV short axis: $33 \pm 4 \mathrm{~mm}$ vs $27 \pm 5 \mathrm{~mm} ; P=.001)$ but only marginal in the control group (RV long axis: $72 \pm 6$ $\mathrm{mm}$ vs $70 \pm 7 \mathrm{~mm} ; P=.08$; RV short axis: $34 \pm 5 \mathrm{~mm}$ vs $33 \pm 5 \mathrm{~mm} ; P=.1$ ). Figure 2 shows the percentage of improvement in echocardiographic measurements of RV remodeling in the 2 groups.

A significant improvement in functional class was observed in both groups, and NYHA class III and IV was present in $0 \%(\mathrm{n}=0)$ and $4 \%(\mathrm{n}=1)$ of patients in the treatment and control groups, respectively $(P=1)$. Six-minute walk test increased in both groups $(P<.001$ from baseline) but was greater in the treatment group $(472 \pm 49 \mathrm{~m}$ vs $435 \pm 51 \mathrm{~m} ; P=.02 ; \Delta=+115 \pm 23 \mathrm{~m}$ vs $+75 \pm 35 \mathrm{~m} ; P=.008$ ).

Medications assumed at follow-up were similar in the treatment and control groups: furosemide $52 \%(\mathrm{n}=11)$ versus $61 \%(\mathrm{n}=13)(P=.78)$; hydrochlorothiazide $23 \%$ $(\mathrm{n}=5)$ versus $42 \%(\mathrm{n}=9), P=.32 ; \mathrm{Ca}^{++}$-channel blockers $28 \%(\mathrm{n}=6)$ versus $33 \%(\mathrm{n}=7), P=.98 ; \beta$-blockers $42 \%$ $(\mathrm{n}=9)$ versus $57 \%(\mathrm{n}=12), P=.50$; and angiotensinconverting enzyme inhibitor/angiotensin receptor blockers $71 \%(\mathrm{n}=15)$ versus $66 \%(\mathrm{n}=14)(P=.98)$.

\section{DISCUSSION}

The main finding of the current study was that concomitant TV annuloplasty prevents progression of TR and

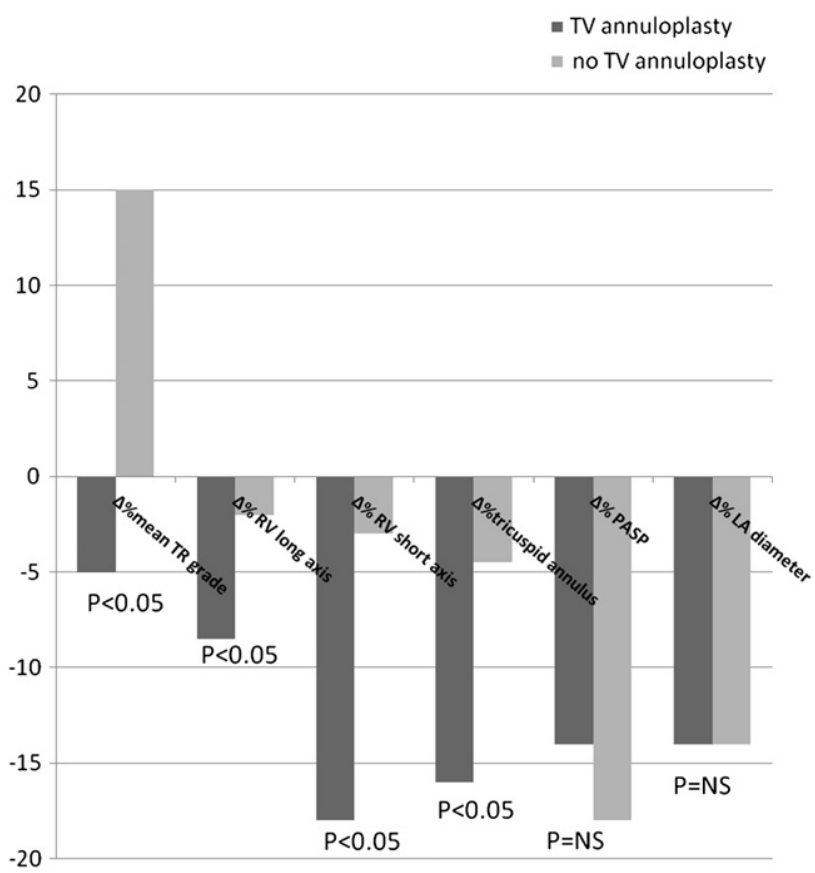

FIGURE 2. Percentage of improvement in echocardiographic measurements of right ventricular $(R V)$ remodeling. $T V$, Tricuspid valve; $P A S P$, pulmonary artery systolic pressure; $L A$, left atrium.

promotes RV reverse remodeling in patients who are referred to mitral valve surgery and who present tricuspid annulus dilatation.

Functional TR is caused mainly by dilatation of the tricuspid annulus, which results from a remodeling process of the RV due to chronic pressure overload. ${ }^{12}$ Treatment of the mitral valve lesion alone only decreases the afterload, but does not correct tricuspid dilatation or directly affect preload or RV function. ${ }^{5}$ As a consequence, complete reverse RV remodeling may not occur, and normalization of pulmonary artery pressures alone will not eliminate TR in many patients. ${ }^{18}$

In addition, several factors influence the occurrence of functional TR: the preload, afterload, and RV function. As occurs for functional mitral regurgitation, these factors can interfere with regard to the severity of TR under different conditions, and significant TR may not be detected by echocardiography despite considerable tricuspid annulus dilatation. Therefore, the regurgitation severity alone assessed by echocardiography is probably not sufficient to screen for secondary $\mathrm{TR}^{5}$ and may not be reliable to identify all patients who require TV annuloplasty.

On the basis of these observations, in recent guidelines the tricuspid annulus dilatation is proposed as a criterion for concomitant TV annuloplasty regardless of the degree of TR, ${ }^{10,11}$ although the European Society of Cardiology recommendations ${ }^{10}$ support a more aggressive approach toward TV repair; meanwhile, the American College of Cardiology/American Heart Association guidelines give 
a more vague, class IIb recommendation for patients with less than severe TR. ${ }^{11}$

The TV annulus diameter may be measured intraoperatively, from the anteroseptal commissure to the anteroposterior commissure, and TV annuloplasty should be considered when the tricuspid annulus diameter is $7 \mathrm{~cm}$ or more. ${ }^{5}$

However, echocardiographic measurement of the tricuspid annulus diameter has been proposed as an alternative approach to the intraoperative assessment. A tricuspid annulus diameter of $40 \mathrm{~mm}$ or more has been demonstrated to be equivalent to $7 \mathrm{~cm}$ intraoperatively (A. Berrebi, personal communication, November 2006). This cutoff accurately identifies patients undergoing mitral valve repair without concomitant TV annuloplasty who have poor echocardiographic outcomes, including significant TR and lack of RV reverse remodeling at follow-up, ${ }^{19}$ and it has been proposed to screen patients for TV repair. ${ }^{10}$

This strategy has been recommended particularly in patients with rheumatic and ischemic disease. ${ }^{20}$ Perplexity remains about the usefulness of concomitant prophylactic TV repair in degenerative mitral valve disease. ${ }^{21}$ Recent findings confirmed that clinically silent, nonsevere TR in this setting is unlikely to progress after mitral valve surgery. ${ }^{22}$ This may be partially because patients with mitral valve leaflet prolapse are more likely to have early mitral valve repair even when they are completely asymptomatic, thus avoiding long-standing RV pressure overload, which predisposes to late functional TR.

In the present study, the advantage of TV annuloplasty was substantial in rheumatic and ischemic disease, but we found no statistically significant trend toward a benefit in degenerative cause. It should be underlined that patients with degenerative mitral valve disease included in the present study presented 2 main baseline characteristics that may partially explain the observed advantage of prophylactic TV annuloplasty that was not reported by others in the same clinical setting ${ }^{22}$ : a higher rate of functional NYHA class III and IV (62.5\% vs $34.6 \%)$ and preoperative history of atrial fibrillation ( $50 \%$ vs $17.5 \%)$. This observation suggested that in the present cohort, patients with a generative cause were less likely to undergo early surgery, thus being exposed to long-standing RV pressure overload. In addition, atrial fibrillation has been demonstrated as a main risk factor for progression of functional TR after mitral valve disease. $^{23}$ These considerations suggest the hypothesis that in degenerative mitral valve disease, TV annuloplasty should be considered regardless of the absolute grade of TR when preoperative atrial fibrillation or congestive heart failure symptoms are present.

\section{Study Limitations}

This study has several limitations. The small sample size precludes meaningful conclusion on differences in major adverse clinical outcomes. In addition, the assessment of primary end point cannot be blinded. The semiquantitative assessment of TR grade was open to operator bias. The grade of TR is dynamic. In such a small study, individual differences in hemodynamic status may have influenced the overall prevalence of TR.

The study is underpowered to detect clinically important differences in operative mortality, and the absence of statistically significant differences in mortality does not permit us to draw any conclusion about operative risk related to TV annuloplasty. TV annuloplasty has been associated with a higher rate of pacemaker requirement. ${ }^{5}$ In the present study, no patients receiving a TV annuloplasty required a pacemaker, and it could be speculated that by using a flexible band the conduction system of the heart is not jeopardized because sutures are not placed in this vicinity.

\section{CONCLUSIONS}

The present study confirmed that a tricuspid annulus diameter of $40 \mathrm{~mm}$ or greater was associated with an increased risk of progression of functional TR when TV repair was not performed. We found that prophylactic TV annuloplasty prevents the progression of functional TR, thus promoting RV reverse remodeling. The advantage of concomitant tricuspid annuloplasty was substantial in rheumatic and functional disease. Future studies with a longer follow-up and larger sample size are required to confirm that prophylactic tricuspid annuloplasty prevents the progression of secondary TR at mid- and long-term followups and that this will transform into clinical benefit for patients.

\section{References}

1. Braunwald NS, Ross J Jr, Morrow AG. Conservative management of tricuspid regurgitation in patients undergoing mitral valve replacement. Circulation. 1967;35(4 Suppl):I63-9.

2. Duran CM, Pomar JL, Colman T, Figueroa A, Revuelta JM, Ubago JL. Is tricuspid valve repair necessary? J Thorac Cardiovasc Surg. 1980;80:849-60.

3. Porter A, Shapira Y, Wurzel M, Sulkes J, Vaturi M, Adler Y, et al. Tricuspid regurgitation late after mitral valve replacement: clinical and echocardiographic evaluation. J Heart Valve Dis. 1999;8:57-62.

4. De Bonis M, Lapenna E, Sorrentino F, La Canna G, Grimaldi A, Maisano F, et al. Evolution of tricuspid regurgitation after mitral valve repair for functional mitral regurgitation in dilated cardiomyopathy. Eur J Cardiothorac Surg. 2008;33: $600-6$.

5. Dreyfus GD, Corbi PJ, Chan KM, Bahrami T. Secondary tricuspid regurgitation or dilatation: which should be the criteria for surgical repair? Ann Thorac Surg. 2005;79:127-32.

6. King RM, Schaff HV, Danielson GK, Gersh BJ, Orszulak TA, Piehler JM, et al. Surgery for tricuspid regurgitation late after mitral valve replacement. Circulation. 1984;70(3 Pt 2):I193-7.

7. Kwon DA, Park JS, Chang HJ, Kim YJ, Sohn DW, Kim KB, et al. Prediction of outcome in patients undergoing surgery for severe tricuspid regurgitation following mitral valve surgery and role of tricuspid annular systolic velocity. Am J Cardiol. 2006;98:659-61.

8. Nath J, Foster E, Heidenreich PA. Impact of tricuspid regurgitation on long-term survival. J Am Coll Cardiol. 2004;43:405-9.

9. McCarthy PM, Bhudia SK, Rajeswaran J, Hoercher KJ, Lytle BW, Cosgrove DM, et al. Tricuspid valve repair: durability and risk factors for failure. J Thorac Cardiovasc Surg. 2004;127:674-85.

10. Vahanian A, Baumgartner H, Bax J, Butchart E, Dion R, Filippatos G, et al. Guidelines on the management of valvular heart disease. The task force on the 
management of valvular heart disease of the European Society of Cardiology. Eur Heart J. 2007;28:230-68.

11. Bonow RO, Carabello BA, Chatterjee K, de Leon AC Jr, Faxon DP, Freed MD, et al. ACC/AHA 2006 guidelines for the management of patients with valvular heart disease: a report of the American College of Cardiology/American Heart Association Task Force on Practice Guidelines (Writing Committee to Revise the 1998 Guidelines for the Management of Patients with Valvular Heart Disease): developed in collaboration with the Society of Cardiovascular Anesthesiologists: endorsed by the Society for Cardiovascular Angiography and Interventions and the Society of Thoracic Surgeons. J Am Coll Cardiol. 2006; 48:e1-148.

12. Fukuda S, Gillinov AM, Song JM, Daimon M, Kongsaerepong V, Thomas JD, et al. Echocardiographic insights into atrial and ventricular mechanisms of functional tricuspid regurgitation. Am Heart J. 2006;152:1208-14.

13. Carpentier A, Deloche A, Dauptain J, Soyer R, Blondeau P, Piwnica A, et al. A new reconstructive operation for correction of mitral and tricuspid insufficiency. J Thorac Cardiovasc Surg. 1971;61:1-13.

14. Roul G, Germain P, Bareiss P. Does the 6-minute walk test predict the prognosis in patients with NYHA class II or III chronic heart failure? Am Heart J. 1998;136: 449-57.

15. Chopra HK, Nanda NC, Fan P, Kapur KK, Goyal R, Daruwalla D, et al. Can two dimensional echocardiography and Doppler color flow mapping identify the need for tricuspid valve repair? J Am Coll Cardiol. 1989;14:1275-7.

16. Foale R, Nihoyannopoulos P, McKenna W, Klienebenne A, Nadazin A, Rowland E, et al. Echocardiographic measurement of the normal adult right ventricle. Br Heart J. 1986;56:33-44.

17. Calafiore AM, Gallina S, Iaco AL, Contini M, Bivona A, Gagliardi M, et al. Mitral valve surgery for functional mitral regurgitation: should moderate-or-more tricuspid regurgitation be treated? a propensity score analysis. Ann Thorac Surg. 2009;3:698-703.

18. Song H, Kang DH, Kim JH, Park KM, Song JM, Choi KJ, et al. Percutaneous mitral valvuloplasty versus surgical treatment in mitral stenosis with severe tricuspid regurgitation. Circulation. 2007;116(11 Suppl):I246-50.

19. Van de Veire NR, Braun J, Delgado V, Versteegh MI, Dion RA, Klautz RJ, et al. Tricuspid annuloplasty prevents right ventricular dilatation and progression of tricuspid regurgitation in patients with tricuspid annular dilatation undergoing mitral valve repair. J Thorac Cardiovasc Surg. 2011;141:1431-9.

20. Bianchi G, Solinas M, Bevilacqua S, Glauber M. Which patient undergoing mitral valve surgery should also have the tricuspid. Interact Cardiovasc Thorac Surg. 2009;9:1009-20

21. Koukoui D, Monakier D, Vaturi M. Natural history and clinical significance of tricuspid regurgitation in patients with mitral valve prolapse and significant mitral regurgitation. Paper presented at: 55th Annual Conference of the Israel Heart Society, Tel Aviv, Israel, April 9-10, 2008.

22. Yilmaz O, Suri RM, Dearani JA, Sundt TM 3rd, Daly RC, Burkhart HM, et al. Functional tricuspid regurgitation at the time of mitral valve repair for degenerative leaflet prolapse: the case for a selective approach. $J$ Thorac Cardiovasc Surg. 2011;142:608-13.

23. Song H, Kim MJ, Chung CH, Choo SJ, Song MG, Song JM, et al. Factors associated with development of late significant tricuspid regurgitation after successful left-sided valve surgery. Heart. 2009;95:931-6.

\section{Discussion}

Dr W. Randolf Chitwood (Greenville, $N C$ ). In this study, you prospectively randomized 44 patients undergoing mitral surgery who had concomitant TR with a dilated annulus to receive or not receive a concomitant band annuloplasty. By preoperative echocardiography, each cohort had less than 2+ TR but a dilated annulus to more than $40 \mathrm{~mm}$ by echocardiography. At 12 months after surgery, the annuloplasty cohort had no TR and only $19 \%$ in the control group had no TR. The absence of TR was reflected in, as you said, reversed remodeling and improvement in patient functionality. On the basis of your data, you are suggesting that we perform prophylactic ringing of the TV.

Many share your view that correction of mitral insufficiency does not correct functional TR automatically. Treatment of this mitral lesion alone decreases the afterload but does not correct tricuspid annular dilatation, preload, or RV function. The TV may have significant pathologic changes even when associated with mild regurgitation. We know that. Moreover, differential loading conditions often make the preoperative echocardiographic assessment inaccurate.

The seminal article by Dreyfus and colleagues ${ }^{5}$ in 2005 recommended that the decision to perform a tricuspid annuloplasty should be based on annular diameter rather than the level of regurgitation, and they considered that an annular diameter of more than $70 \mathrm{~mm}$ (now, this was measured directly in the operating room, not on echocardiography, and that was more than twice the diameter of the normal valve) was an indication for a concomitant ring or repair. Your study has shown that RV reverse remodeling is good and functionality is great. What was the size of the valve annulus when you were in the operating room? Professor Mohr subscribes to the same thing in Leipzig if it is more than $65 \mathrm{~mm}$.

In contrast, at the Mitral Valve Conclave in New York City, Rakesh Suri from the Mayo Clinic reported a large series of patients with different levels of tricuspid insufficiency. They showed that grades 1 and 2 regurgitation progressed only slightly over time and that atrial fibrillation was a risk factor. So lower levels of TR did not affect long-term survival, and they did not put a ring in. That is in contradistinction to what you are saying.

Many surgeons still do not agree with a "prophylactic tricuspid annuloplasty." Moreover, there is even disagreement between our guidelines in Europe and the United States. In Europe, a class IIa indication exists for moderate TR with a dilated annulus in a patient undergoing a mitral valve operation, but in the United States, our guidelines state that a tricuspid annuloplasty "may be considered" a class IIb indication in the presence of annular dilatation and pulmonary hypertension. Therefore, there is a significant conundrum between surgeons and cardiologists on what to do.

I have 3 questions for you. Considering that the tricuspid annular size can vary with loading conditions and that echocardiography measurements can be inaccurate, do you measure the annulus intraoperatively? I think you said you just use the anterior leaflet to size the ring or band you were using. Do you put any credence in the intraoperative measurement?

Dr Benedetto. We decided to measure the tricuspid annulus with preoperative echocardiography because we think that intraoperative measurement is not reliable or easily reproducible. We found an agreement between the judgment of tricuspid dilatation assessed by preoperative echocardiography and intraoperative examination.

Dr Chitwood. Did you perform transesophageal echocardiography in the operating room or is this all transthoracic?

Dr Benedetto. In the operating room we did not perform transesophageal echocardiography to measure the annulus but only to assess the result of TV repair.

Dr Chitwood. The second question is, Jim Gammie recently suggested-and this will be published in the Annals of Thoracic Surgery, it is in press-using an undersized ring to repair the TV. They used no ring larger than $28 \mathrm{~mm}$. What is your optimal size and does it matter as long as it is a smaller annulus? What do you think the optimal size is?

Dr Benedetto. The median ring size in our series was $32 \mathrm{~mm}$. We select the ring size on the basis of the septal leaflet attachment, and we did not undersize this measure. 
Dr Chitwood. Many patients who do have moderate to severe tricuspid insufficiency, and have a repair and the ventricle changes, develop recurrent tricuspid disease. What do you do when you have that dilated ventricle, pulmonary hypertension, and more than moderate regurgitation? Do you just put a ring in or do you augment? What do you do?

Dr Benedetto. We are aware that functional tricuspid pathology is similar to functional mitral regurgitation and that the result of tricuspid repair is strongly related to the preoperative RV conditions. In patients with a highly remodeled right ventricle, the risk of a failure is high. However, we do not adopt an alternative surgical strategy in these cases.

Dr Patrick McCarthy (Chicago, Ill). By way of disclosure, I am the inventor of the MC3 ring (Edwards Lifesciences, Irvine, Calif). I was interested in the atrial fibrillation at 1 year. Do you have any data on how common that was? Was that, for instance, more common in the control group and did it correlate with the 6-minute walk test? Excellent article, and it was good to see a prospective randomized surgical trial.

Dr Benedetto. For the small sample size, subgroup analysis was not possible, but we have the data for atrial fibrillation. Nine patients in the annuloplasty group had a history of atrial fibrillation, and 6 of them underwent a Maze procedure. Because 3 of them had a left atrium greater than $60 \mathrm{~mm}$, we decided not to perform this procedure in these patients. Therefore, at 1-year follow-up, 5 patients treated had sinus rhythm and only 1 patient had atrial fibrillation. In our annuloplasty group, of 12 patients with a preoperative history of atrial fibrillation, 9 were treated because the others had a left atrium greater than $60 \mathrm{~mm}$. Only 1 patient had recurrence of atrial fibrillation. Overall, we had persistent sinus rhythm in approximately $80 \%$ of patients treated for atrial fibrillation.

Dr Norberto De Vega (Malaga, Spain). I rise to congratulate Dr Benedetto and colleagues for the elegant presentation. Forty years ago, a Canadian surgeon, Pierre Groudin, published a seminal article in the Journal, "The Tricuspid Valve: A Surgical Challenge." Since then, that was 40 years, for too many years we surgeons have been trying to find the best technique to address the problem instead of trying to find the best indication. Unfortunately, many times we have followed the indications of the cardiologists, who have been wrong. Nowadays, I believe that in most mitral surgical cases, the tricuspid annulus should be fixed or reduced. It can be done without any added risk and can prolong the well-being of many patients for many years.

Have you ever tried any other technique apart from the ring? I know that my Indian and Chinese friends who probably are here would agree that $\$ 2000$ for this prophylactic surgery may be too much for many patients.

Dr Benedetto. We decided to perform tricuspid annuloplasty with a ring because recent evidence suggests that ring annuloplasty is associated with better results than suture annuloplasty. However, the policy in our department is to routinely perform De Vega suture annuloplasty. In the present study, we used ring annuloplasty to avoid any criticism, but outside of the present study, we have optimal results with the De Vega technique. 